publication. Zahlan himself is aware of the shortcomings of his methodology. However, no one is really any wiser at the end of the exercise.

As Egypt has the most highly developed scientific infrastructure in the Middle East, Zahlan appropriately devotes a whole chapter to the country. It is very much a historical discussion that traces science development in Egypt from 1951. An attempt is made to chart the development of scientific activity by measuring the increases in BSc and $\mathrm{PhD}$ degree holders (what is an Egyptian $\mathrm{PhD}$ worth, in real scientific terms, anyway?). Most of the statistics are taken from government ministries and technical institutes and no attempt is made to indicate the level of reliability of the figures. After Egypt, scientific activities in "selected countries" are presented: five pages on Kuwait, just over two on Iraq, less than a page on Saudi Arabia - which has one of the most rapidly expanding scientific bases in the Middle East, with astronomical sums being spent on science and technological development - and a half-page on Syria. Is that all that is happening in these countries and in the Middle East as a whole? Is nothing going on in Sudan, Algeria, Tunisia and Jordan?

After a similarly patchy and brief treatment of scientific manpower, we reach the last three chapters on funding, international and regional cooperation, and science policy, where at least an attempt has been made to be more thorough. The chapter on funding does manage to bring out both the channels being developed to fund scientific research and development and the resources available to capital-rich and capital-poor Arab states. The chapter on international and regional cooperation amounts to little more than the minutes of meetings of the Conference of Ministers of Arab States Responsible for the Application of Science and Technology to Development, and relies heavily on national papers submitted by Arab states to the recently held UN Conference on Science and Technology for Development. It is certainly not scholarship, neither is it good journalism, but it works as an account of recent history. This is also true of the chapter on science policy; here the commentary suffers by uncritical reproduction of material from brochures and annual reports such as that of Cairo's National Research Centre.

So, what value can one place on Science and Science Policy in the Arab World? The book has little of value to say about science policy, and even less about science, in the Middle East. But the book works, to a certain extent, as a history of science in the Middle East in general, and Egypt in particular, during the 1950s and 1960s. It is surprising that Zahlan has nothing much to say about recent - post-1975 developments in science and technology. $\mathrm{He}$ seems to have overlooked the controversies about "Arabization" of science, planning and developing technical institutions and universities, scientific bureaucracies and the debate on Islamic science. Perhaps these omissions are deliberate, but some discussion of these issues would have saved him from the accusation that the book is remarkably boring. Perhaps Zahlan feels that he has

\section{Landau in retrospect}

\section{H.B.G. Casimir}

Landau: A Great Physicist and Teacher. By Anna Livanova. Pp. 217. (Pergamon: 1980.) £10, $\$ 22.50$.

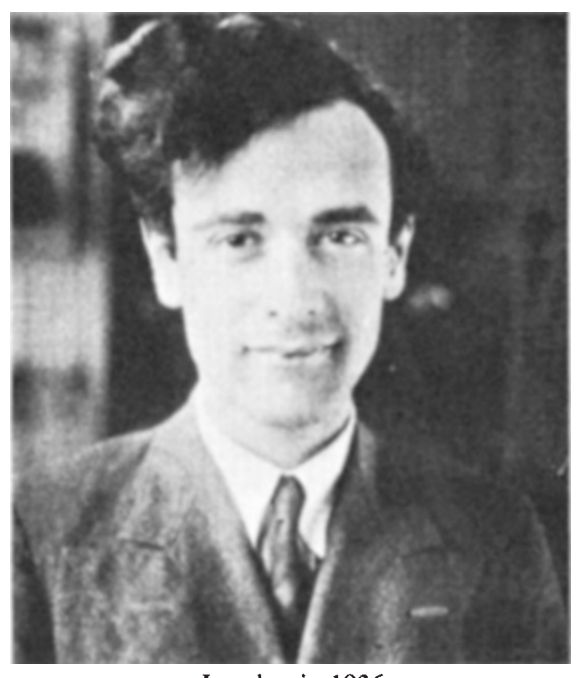

Landau in 1936

LEV Davidovich Landau (1908-1968) was a brilliant theoretical physicist, an outstanding teacher and a striking personality, with an influence spreading far beyond the circle of his students and coworkers; his merciless criticism may have antagonized some of its victims, but he was most helpful and encouraging to anyone he considered worth helping. These characteristics are clearly brought out in Anna Livanova's well-written book. Although it is neither an exhaustive biography nor a critical appraisal of the whole of Landau's contributions to physics, the author has succeeded admirably in re-creating the image of this great man and in explaining to a general reader his ways of working and teaching.

The book opens with a brief biography. Landau was born at Baku and entered the university there at the age of 14. In 1924 he moved to Leningrad, graduating in 1927. Livanova gives a short but lively description of his student days. He learnt a little from his professors, quite a bit from discussions with fellow students - but most just by himself.

In 1929 he set out on an extended visit to western Europe and England. He went to see Pauli at Zürich, collaborated there with Peierls and wrote his famous paper on said it all elsewhere in one of his many excellent publications. If this is so, then why write such an empty book?

Ziauddin Sardar is Middle East Science Consultant to New Scientist and author of Science, Technology and Development in the Muslim World.

diamagnetism (the description of which, by Livanova, leaves something to be desired). At Cambridge he met Kapitza, the beginning of a lifelong friendship, but of even greater influence on Landau were his contacts with Niels Bohr at Copenhagen. Livanova reports that Landau later regarded Bohr as his one and only teacher. That may seem surprising; I cannot think of two prominent physicists who differed more widely in their approach to teaching. Livanova calls attention to this difference, but in my opinion she does not sufficiently stress this point. I believe Bohr's influence was so important because his way of looking at physics was complementary to Landau's self-taught virtuosity. Landau had far more in common with Pauli in that they possessed comparable intellectual power and mathematical skills, and both could on occasion be redoubtable critics. Even so, there was a profound difference in their choice of subjects.

In 1932 Landau became head of the theoretical division of the Ukrainian Physicotechnical Institute at Kharkov. There he began teaching in earnest, collaborated with the experimentalists especially with Shubnikow who had set up a cryogenic laboratory - and published a number of important papers. He left Kharkov in 1937 for Moscow and there he remained as head of the theoretical division of Kapitza's Institute of Physical Problems until his death in 1968; he always refused to become head of an institute of his own.

After a serious motor car accident in 1962, Landau became practically an invalid. One can sympathize with Anna Livanova in not entering into details concerning these later years, but I find it regrettable that, although she hints at difficulties at Kharkov, she does not mention that Shubnikow was arrested and never heard of again, and that Landau spent about one year in prison in 1938 and 1939 and might have perished but for Kapitza's courageous intervention.

For me, the most fascinating chapter is that concerned with "The School of Landau'". This shows Landau at the height of his powers and gives a lively picture of his particular style and methods.

About half of the book is devoted to a description of Kapitza's work on the superfluidity of liquid helium and Landau's theoretical work in this field. The author preferred to consider one important and characteristic contribution of Landau's in detail instead of discussing superficially the whole of his work, and in 
this she has been most successful in epitomizing the essence of Landau as a scientist. I have only one objection. No mention is made of the analogous and simultaneous experimental work of Allen and Misener at Cambridge, or of the theoretical work of F. London and of Tisza, who predicted second-sound several years ahead of Landau. The work of Landau was hardly influenced by these parallel developments, but the reader should know of them and that Landau's work, important though it was, was neither the only nor the final step towards a theory of superfluidity.

The final chapter, "Dau Away From Physics", recounts some amusing anecdotes but is hardly profound analysis. When I knew Landau at Copenhagen in 1930 and 1931 he was in a state of transition from shyness and reticence to the sociable and self-assured man of later years. He was then already classifying all things. Physicists, people in general and girls in particular, books, poems, motion pictures, they all received marks from one to five (one the very best, five the worst and three just acceptable). Such grading also entered into his discussion of human relations. A couple where the man was a five, whereas the wife ranked a full three was unsatisfactory and should be broken up. In retrospect such considerations seem to me the immature and not even very witty selfdefence of a sensitive and vulnerable man. Livanova takes them more seriously. In those faraway days Landau was not a happy man. Livanova mentions his claim that by his rational approach to human problems he succeeded in teaching himself to be happy. Did he really? I wonder.

H.B.G. Casimir studied theoretical physics at Leiden, Copenhagen and Zürich, worked in low temperature physics at Leiden and later joined the Philips Company at Eindhoven. He was for several years President of the European Physical Society.

\section{Emilio Segrè on physics and on physicists}

\section{John Stachel}

\section{From X-Rays to Quarks: Modern} Physicists and Their Discoveries. By Emilio Segrè. Pp.337. (W.H. Freeman: 1980.) Hardback $\$ 20, £ 11.80$; paperback $\$ 9.95, £ 5.40$.

EMILIO Segrè is one of that group of extraordinarily gifted physicists that gathered around Enrico Fermi in the late 1920s, a group whose members contributed so much to the development of nuclear and elementary particle physics in the ensuing decades. Like Fermi, Segrè came to the United States in 1938 and worked on the A-bomb project during the Second World War. After the War he returned to Berkeley, where he worked primarily in high-energy physics. An experimentalist,

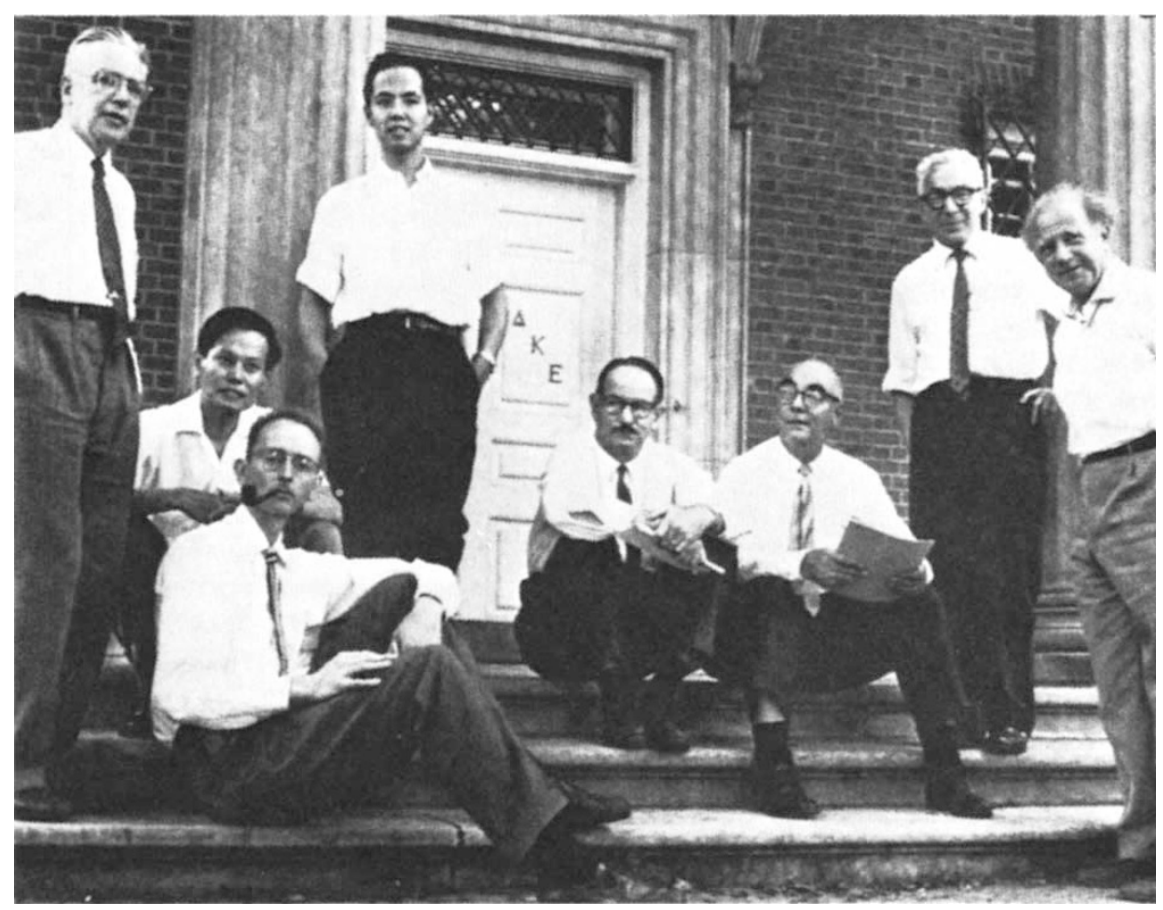

Eight Nobel prize winners at the 1960 Rochester meeting. From left: E. Segrè, C.N. Yang, O. Chamberlain, T.D. Lee, E. McMillan, C.D. Anderson, I.I. Rabi and W. Heisenberg.

he shared the 1959 Nobel Prize in physics with Owen Chamberlain for the discovery of the anti-proton.

This book is based on lectures in which, as he says, "I tried to show not only the main discoveries but also the way they were reached, the personalities of the leading physicists and the errors committed before the right path was found". A prospective reader should not be misled by the title: the book is about the development of atomic, nuclear and elementary particle physics and ". . . does not pretend to be a history of modern physics. It is, rather, an impressionistic view of the events as they appeared to me during my scientific career ...".

Segrè gives fascinating accounts, from his perspective, of the discovery of the electron, X-rays, radioactivity; the old and new quantum theories and special relativity; nuclear structure and nuclear energy; particle accelerators and highenergy physics. The discussion is quite ample until about 1960. More recent developments, and accounts of related areas of physics, are treated in much less detail. For example, quantum electrodynamics, lasers and masers, the Mössbauer effect, superconductivity, astrophysics and biology are crowded into one chapter of 20 pages. In a final chapter, "Conclusions", Segrè points out trends toward greater specialization, industrialization, abstraction, and growing ties with technology in the current development of physics.

While an attempt is made to make the achievements of the major physicists "understandable to the layman", "Some knowledge of physics ... is necessary". Most formulae, however, are relegated to ten appendices ranging from "Stefan's law; Wien's law", to "Quantum Mechanics in a Nutshell'".

Most semi-popular survey books of this type seem to be written either by theoretical physicists or non-physicists, and tend to overemphasize theoretical achievements and/or adopt an overawed attitude towards modern experimental techniques. It is therefore valuable to have a book written by such an eminent experimentalist. While he does not neglect the theoretical developments or the theorists, there is a better sense of balance, and of the interplay between experimental achievement and theoretical advance, than in similar books I have read. Since it is an avowedly personal account, Segrè does not hesitate to give his evaluations of the styles of work and personalities of the physicists he is discussing, or to illuminate the text with personal anecdotes and reminiscences. The book is also enlivened by numerous well-chosen illustrations, which really add a great deal of impact to the text. A reader comparing photographs of laboratories and sketches of experimental set-ups in the first few and in the last few chapters, for example, cannot avoid being struck by the growing industrial- 